\title{
Escalas de Dor: Referencial para Escolha em um Hospital Geral
}

Juliana Miyuki do Prado ${ }^{1}$

Silvia Helena Frota Mendonça²

Denise Cavallini Alvarenga ${ }^{3}$

\section{Introdução}

A dor é definida como uma "experiência sensitiva e emocional desagradável associada ou relacionada à lesão real ou potencial dos tecidos". Necessita ser identificada e avaliada de forma adequada por meio de escalas elaboradas e validadas para utilização de acordo com o perfil definido na construção.

Não existe um instrumento único que permita a mensuração objetiva de uma experiência tão complexa e individual.

Durante a revisão do protocolo de gerenciamento da dor, verificou-se a necessidade de adequação das escalas de avaliação de dor.

\section{Objetivo}

Descrever o processo de adequação das escalas de avaliação de dor em um hospital geral terciário de São Paulo, com 700 leitos, que atende pacientes de todas as faixas etárias.

\section{Método}

Foi feito a Revisão do protocolo de gerenciamento da dor pela equipe multidisciplinar.

Os critérios seguidos para escolha das novas escalas foram: a facilidade de aplicação, adequação às faixas etárias, condição clínica, tipo de atendimento (ambulatorial, pronto socorro, internados e em medicina diagnóstica e terapêutica) e disponibilidade no sistema de informação hospitalar.

Para os pacientes adultos, foram considerados os níveis de consciência, alfabetização e sedação. Para os pacientes pediátricos, além desses critérios, foi analisada a indicação das escalas de acordo com a faixa etária.

\section{Resultados}

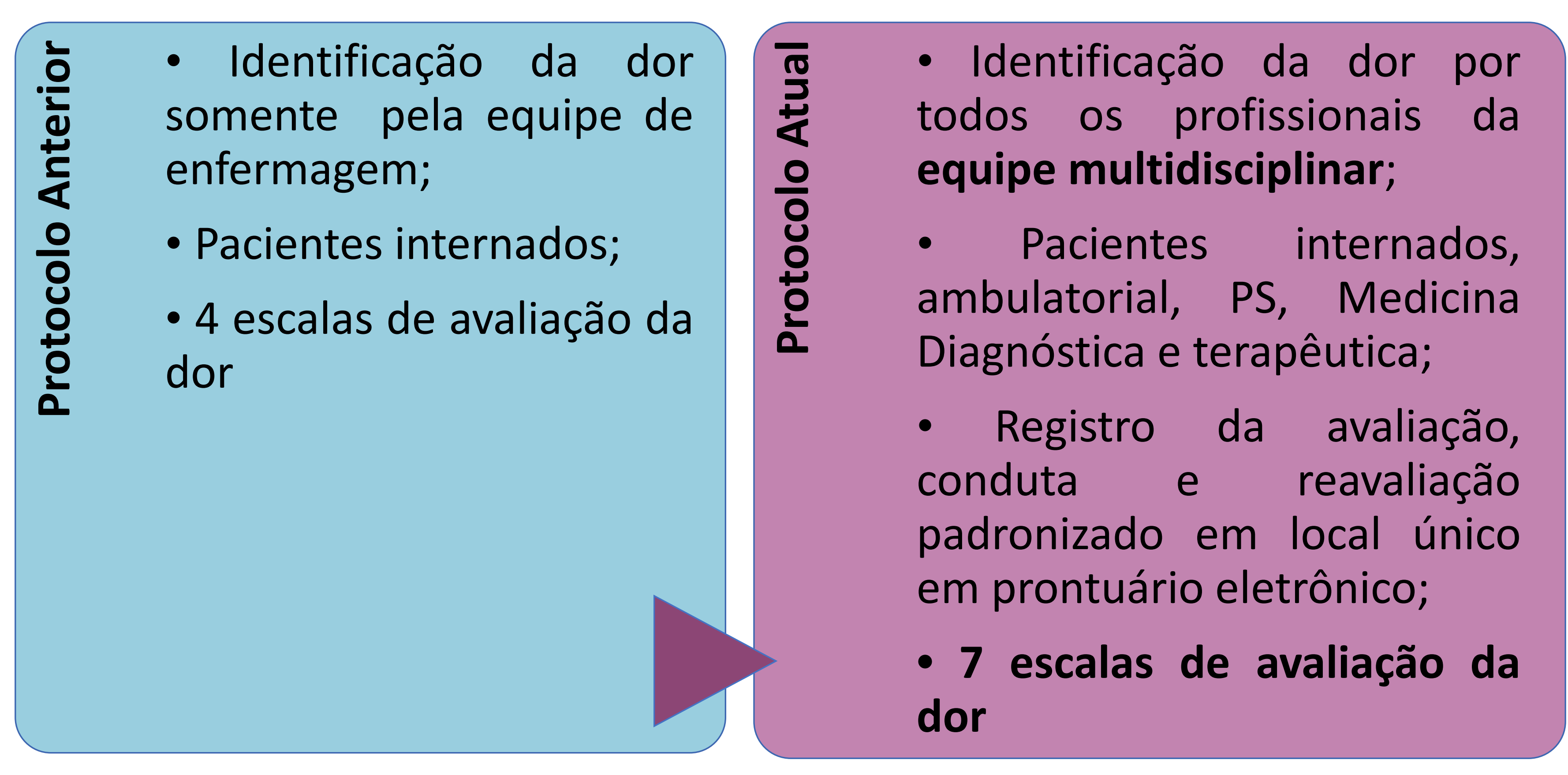

\section{Escalas de Dor:}

\begin{tabular}{l|l|}
\hline $\begin{array}{l}\text { - Categórica Numérica } \\
\text { - Faces }\end{array}$ & $\begin{array}{l}\text { - Categórica Numérica } \\
\text { - FNAID } \\
\text { - FPS }\end{array}$ \\
- NIPS \\
- FLACC \\
- COMFORT B \\
\hline $\begin{array}{l}\text { Pacientes } \\
\text { Adultos }\end{array}$
\end{tabular}

A equipe multidisciplinar foi treinada com foco na aplicação de escalas multidimensionais e na integração das ações para garantir o gerenciamento efetivo.

\section{Conclusão}

A complexidade do perfil de atendimento da instituição determinou a ampliação e adequação do uso de escalas comportamentais, a inclusão de outros grupos profissionais na identificação, avaliação e tratamento da dor e abrangência para pacientes ambulatoriais e externos. 